\title{
Electrochemical approach of Kalmegh leaf extract on the corrosion behavior of aluminium alloy in alkaline solution
}

\author{
Namrata Chaubey ${ }^{1} \cdot \operatorname{Vinod}$ Kumar $\operatorname{Singh}^{1} \cdot$ M. A. Quraishi $^{2}$
}

Received: 30 October 2015/Accepted: 7 November 2016/Published online: 14 November 2016

(c) The Author(s) 2016. This article is published with open access at Springerlink.com

\begin{abstract}
Introduction The effect of Kalmegh leaf extract (KLE) on the corrosion behavior of aluminium in $1 \mathrm{M} \mathrm{NaOH}$ solution was studied using electrochemical impedance spectroscopy (EIS) and potentiodynamic polarization (PDP) studies.

Results Inhibition efficiency $(\eta \%)$ increased with increasing the concentration of extract and maximum inhibition efficiency observed is 82.24 and $82.45 \%$ from EIS and PDP studies, respectively, at higher concentration.

Conclusion The adsorption of the inhibitor on aluminium surface was in accordance with the Langmuir adsorption isotherm. Potentiodynamic polarization study showed mixed type inhibition with predominantly cathodic effect. SEM and AFM study was carried out to support the experimental inhibition data.
\end{abstract}

Keywords Aluminium alloy · Corrosion · EIS · SEM

\section{Introduction}

Aluminium, with high energy density $\left(8.1 \mathrm{~kW} \mathrm{~h} \mathrm{~kg}^{-1}\right)$ and an electrode potential of $2.35 \mathrm{~V}$ vs. standard hydrogen electrode (SHE) are known for wide range of applications in the various industries such as automotive, aerospace, construction and electrical power generation [1]. The behavior

M. A. Quraishi

maquraishi.apc@itbhu.ac.in; maquraishi@rediffmail.com

1 Department of Chemistry, Udai Pratap Autonomous College, Varanasi 221002, India

2 Department of Chemistry, Indian Institute of Technology, Banaras Hindu University, Varanasi 221005, India of aluminium was extensively studied in the context of corrosion where the research work was focused on the protection of the metal from anionic attacks. Aluminium dissolution was also studied in term of hydrogen production, but one of the advantageous applications of aluminium corrosion is metal/air batteries in which aluminium is used as anode material in alkaline medium. The metal/air batteries of aluminium have been widely used for electric vehicle propulsion [2]. When exposed to alkaline medium, aluminium, suffers substantial corrosion attack which induces fuel consumption during standby and columbic loss on discharge. It reduces the efficiency of battery and sometimes causes explosion as a result of hydrogen build up [3]. To improve and optimize the performance of these batteries, the corrosion rate of aluminium alloy must be reduced by the use of inhibitors which can raise the hydrogen evolution over potential without significant reduction in the rate of aluminium oxidation.

A survey of literature reveals that various types of organic and inorganic compounds have been used for the protection of aluminium corrosion in alkaline solution [4-7]. However, the use of chemical inhibitors has been limited because of being synthetic chemicals, highly expensive, and toxic to the environment. Therefore, it is worthwhile to give attention towards a very cheap and environmentally safe research for corrosion inhibition of aluminium in alkaline solution. In view of this, various plants extracts such as, Damsissa [8], Lupinus varius [9], Mesembryanthemum nodiflorum [10], Raphia hookeri [11], Phyllanthus amarus [12], Cantaloupe [13], Gossipium hirsutum [14], livestock dung [15], Gum Arabic [16] and Vigna unguiculata [17] have been proved as efficient inhibitors by various researchers on aluminium in alkaline solution. Plant extracts are incredibly rich source of naturally synthesized organic compounds that can be extracted 
using simpler techniques with low cost [18]. As a contribution to the current interest on environmentally friendly inhibitors, this study investigates the inhibition effect of Kalmegh (Andrographis paniculata) leaves extract on AA in $1 \mathrm{M} \mathrm{NaOH}$ and observed maximum inhibition efficiency is $82.24 \%$ at higher concentration.

Kalmegh ( $f$. Acanthaceae) is an annual herbaceous plant, native to India and Srilanka. The plant is known in northeastern India as "king of bitter". It is one of the bitter plants that are used in traditional medicine and is a great benefit to Unani, Ayurveda and Homeopathy. The plant leaves were chosen due to (a) presence of water soluble active constituents (b) ease of availability and (c) environmental friendliness.

Kalmegh (Andrographis paniculata) leaf extract is composed of numerous naturally occurring organic compounds. Andrographolide, Neoandrographolide, Paniculide-A, Paniculide-B, Paniculide-C, have been isolated from the whole plant and leaves which contain multiple bonds through which they get adsorbed on the AA surface. As reported in literature, Andrographolide is found to be major constituent extracted from the leaves of the plant which is a bicyclic diterpenoid lactone (given in Fig. 1) $[19,20]$.

The objective of this investigation is to evaluate the corrosion inhibition effect of KLE on aluminium alloy in $1 \mathrm{M} \mathrm{NaOH}$ solution. The inhibition performance is examined by potentiodynamic polarization (PDP) and electrochemical impedance spectroscopy (EIS). The experimental results were complemented well with SEM and AFM investigation.

\section{Experimental details}

\section{Materials and test solution}

The corrosion test was performed on the aluminium alloy coupons having the composition given in Table 1. The test solution, $1 \mathrm{M} \mathrm{NaOH}$ was prepared by dissolving $40 \mathrm{~g}$ of $\mathrm{NaOH}$ in $1000 \mathrm{ml}$ of double distilled water.

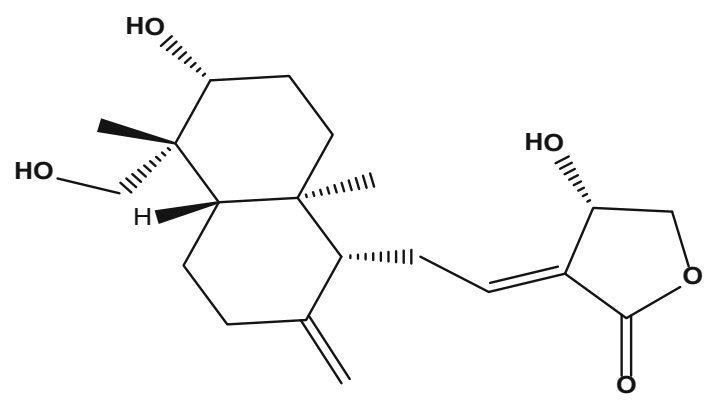

Fig. 1 Molecular structure of andrographolide

\section{Preparation of inhibitor solution}

Kalmegh plants were collected from the campus of Banaras Hindu University. Leaves were dried and grind to powdered form. The $5 \mathrm{~g}$ of powder was added to $500 \mathrm{ml} 1 \mathrm{M}$ $\mathrm{NaOH}$ solution in a round bottom flask and refluxed for $1 \mathrm{~h}$. Thereafter, the mixture was cooled and filtered. The residue of all the leaves were dried and weighed. The volume of the filtrate was maintained up to $100 \mathrm{ml}$ which was used as stock solution. The different concentrations of stock solution were taken for the corrosion test.

\section{Electrochemical experiments}

The AA coupons used in electrochemical tests were mechanically cut into $7.0 \times 1.0 \times 0.035 \mathrm{~cm}$ dimension. Testing systems consisted of a three electrode cell configuration. AA with an area of $1 \mathrm{~cm}^{2}$ was used as working electrode. A platinum wire and a saturated calomel electrode (SCE) i.e., $\left(\mathrm{Cl}^{-}\left|(4 \mathrm{M}) \mathrm{Hg}_{2} \mathrm{Cl}_{2}(s)\right| \mathrm{Hg}(l) \mid \mathrm{Pt}\right)$ were used as counter and reference electrodes, respectively. The three electrode cell connected to the Gamry Potentiostat/ Galvanostat (Model 300) instrument. All the tests were performed in the absence and presence of different concentration of KLE in $1 \mathrm{M} \mathrm{NaOH}$ solution at $303 \mathrm{~K}$. The data obtained from electrochemical measurements was analyzed using Echem analyst 5.0 software. The tests were performed after 15 min immersion of $\mathrm{AA}$ in $1 \mathrm{M} \mathrm{NaOH}$ solution in the absence and presence of inhibitor. EIS measurements were carried out at OCP over a frequency range of $10^{5}-10^{-2} \mathrm{~Hz}$ using a $10 \mathrm{mV}$ sine wave $\mathrm{AC}$ voltage. Finally, the Potentiodynamic polarization test was carried out by sweeping the electrode potential from -0.25 to $+0.25 \mathrm{~V}$ vs. OCP at a scan rate of $1 \mathrm{mV} / \mathrm{s}$.

\section{Surface analysis}

The surface morphologies of AA samples after exposure to $1 \mathrm{M} \mathrm{NaOH}$ for $3 \mathrm{~h}$ in the absence and presence of KLE were examined by SEM and AFM. The SEM of the AA surface was performed at an accelerating voltage of $5000 \mathrm{~V}$ and 5000 $\mathrm{X}$ magnification using FEI Quanta 200F microscope. The AFM was performed using NT-MDT multimode, Russia, controlled by solver scanning probe microscope controller.

\section{Results and discussion}

\section{Electrochemical measurement}

\section{Potentiodynamic polarization study}

The effect of KLE on the corrosion rate of AA in $1 \mathrm{M}$ $\mathrm{NaOH}$ was studied using Tafel polarization technique. 
Table 1 Chemical composition (wt $\%$ ) of the AA used

\begin{tabular}{lllllllllll}
\hline $\mathrm{Si}$ & $\mathrm{Fe}$ & $\mathrm{Cu}$ & $\mathrm{Mn}$ & $\mathrm{Mg}$ & $\mathrm{Zn}$ & $\mathrm{Cr}$ & $\mathrm{Ti}$ & $\mathrm{V}$ & $\mathrm{Ga}$ & $\mathrm{Al}$ \\
\hline 0.77 & 0.93 & 0.02 & 0.11 & 0.01 & 0.01 & 0.05 & 0.02 & 0.01 & 0.01 & Balanced \\
\hline
\end{tabular}

Figure 2 represents the potentiodynamic polarization curves for $\mathrm{AA}$ in $1 \mathrm{M} \mathrm{NaOH}$ at different concentrations of $\mathrm{KLE}$ at $303 \mathrm{~K}$. The decrease in corrosion rate occurs by shifting the anodic curves to more positive potentials and cathodic curves to more negative potentials, and to the lower values of corrosion current densities (Fig. 2). Table 2 shows the values of electrochemical parameters i.e., corrosion potential $\left(E_{\text {corr }}\right)$, corrosion current density $\left(i_{\text {corr }}\right)$, cathodic Tafel constant $\left(\beta_{\mathrm{c}}\right)$ and anodic Tafel constant $\left(\beta_{\mathrm{a}}\right)$ along with percentage inhibition efficiency $(\eta \%)$.

The inhibition efficiency (IE\%) was calculated by following equation [21]:

$\eta \%=\frac{i_{0}-i}{i_{0}} \times 100$

where, $i_{0}$ and $i$ are the corrosion current densities in the absence and presence of inhibitor, respectively.

The data of Table 2 and Fig. 2 shows that the $i_{\text {corr }}$ value is higher in $\mathrm{NaOH}$ but the presence of KLE causes a prominent decrease in the corrosion rate i.e., prominently shifts the cathodic curves to lower values of current densities. The maximum decrease in $i_{\text {corr }}$ value (16.9 $\mathrm{mA} \mathrm{cm}{ }^{-2}$ ) and maximum $\eta \%(82.4)$ is observed at 1.0 $\mathrm{g} \mathrm{L}^{-1}$.

It has been reported that anodic dissolution of aluminium in the alkaline medium takes place through a stepwise addition of surface hydroxyl species, culminating in the chemical dissolution of $\mathrm{Al}(\mathrm{OH})_{3}$ in the presence of surface oxide film. The overall anodic reaction taking place in the corrosion of aluminium in the alkaline solution is represented as under [22-25]

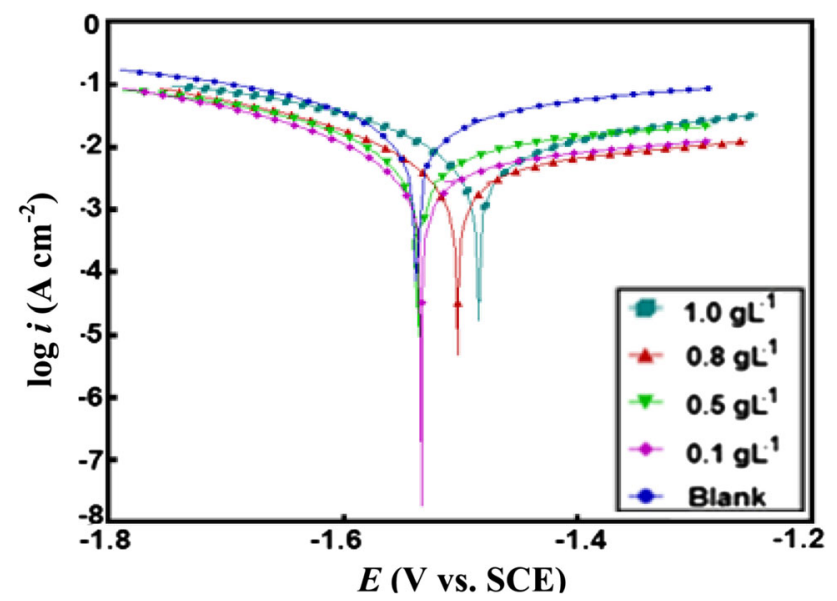

Fig. 2 Tafel curves for AA in $1 \mathrm{M} \mathrm{NaOH}$ in absence and presence of different concentrations of KLE at $303 \mathrm{~K}$
$\mathrm{Al}_{(\mathrm{SS})}+\mathrm{OH}^{-} \rightarrow \mathrm{Al}(\mathrm{OH})_{\mathrm{ads}}+e^{-}$

$\mathrm{Al}(\mathrm{OH})_{\mathrm{ads}}+\mathrm{OH}^{-} \rightarrow \mathrm{Al}(\mathrm{OH})_{2 . \mathrm{ads}}+\mathrm{e}^{-}$

$\mathrm{Al}(\mathrm{OH})_{2 . \text { ads }}+\mathrm{OH}^{-} \rightarrow \mathrm{Al}(\mathrm{OH})_{3 . \text { ads }}+e^{-}$

$\mathrm{Al}(\mathrm{OH})_{3 . \mathrm{ads}}+\mathrm{OH}^{-} \rightarrow \mathrm{Al}(\mathrm{OH})_{4}^{-}+e^{-}$

The cathodic reaction on the film covered electrode surface is the reduction of water [26]:

$2 \mathrm{H}_{2} \mathrm{O}+3 \mathrm{e}^{-} \rightarrow \mathrm{H}_{2+} 2 \mathrm{OH}^{-}$(cathodic reaction)

However, the linear cathodic and anodic polarization curves indicate that the presence of KLE does not affect the mechanism of corrosion reaction at anodic and cathodic sites. No noticeable shift occurs in the values of anodic and cathodic Tafel constants in inhibited system as compared to blank. Thus, KLE behaves as mixed type inhibitor. Moreover, the addition of KLE shifts the corrosion potential $\left(E_{\text {corr }}\right)$ slightly in the negative direction and reduces both the anodic and cathodic current densities. Thus, the inhibitor behaves as mixed type with predominantly cathodic.

\section{Electrochemical impedance spectroscopy}

The corrosion behavior of AA is investigated using electrochemical impedance technique at different concentration of KLE in $1 \mathrm{M} \mathrm{NaOH}$ solution at $303 \mathrm{~K}$. With the help of Nyquist plot in Fig. 3a, it was found that the diameter is increased with increasing the concentration of KLE and it may be attributed to increasing the resistance but the shape remains same throughout the concentrations, indicating that there is no change in corrosion mechanism occurring through the KLE. The impedance spectra (Fig. 3a) is characterized by a capacitive time constant at higher frequency (HF), second capacitive time constant at lower frequency (LF), separated by an inductive time constant at medium frequency (MF) values.

The capacitive loop at $\mathrm{HF}$ is ascribed to the formation of protective (oxide) layer. According to Brett [27], the first capacitive time constant is associated with the reaction of aluminium oxidation at the metal/oxide/electrolyte interface. In this process, the formation of $\mathrm{Al}^{+}$ions at the metal/ oxide interface and their migration through oxide layer to the oxide/solution interface occur due to high electric field strength, where they become oxidized to $\mathrm{Al}^{3+}$ [28]. This is attributed to the fact that these processes determined by capacitive time constant could either be suggested by overlapping of time constants or by the assumption that one process dominates and, therefore, excludes the other 
Table 2 Potentiodynamic polarization parameters for AA in $1 \mathrm{M} \mathrm{NaOH}$ in the absence and presence of different concentration of KLE at $303 \mathrm{~K}$

\begin{tabular}{llllll}
\hline KLE $\left(\mathrm{g} \mathrm{L}^{-1}\right)$ & \multicolumn{5}{l}{ Tafel polarization } \\
\cline { 2 - 5 } & $i_{\text {corr }}\left(\mathrm{mA} \mathrm{cm}^{-2}\right)$ & $E_{\text {corr }}(\mathrm{V} / \mathrm{SCE})$ & $\beta_{\mathrm{a}}(\mathrm{mV} / \mathrm{dec})$ & $\beta_{\mathrm{c}}(\mathrm{mV} / \mathrm{dec})$ & $\eta(\%)$ \\
\hline 0.0 & 96.3 & -1.508 & 1001 & 504 & - \\
0.2 & 30.2 & -1.518 & 1230 & 358 & 70.0 \\
0.5 & 28.8 & -1.516 & 919 & 353 & 70.1 \\
0.8 & 21.6 & -1.518 & 1018 & 298 & 77.5 \\
1.0 & 16.9 & -1.520 & 1202 & 266 & 82.4 \\
\hline
\end{tabular}
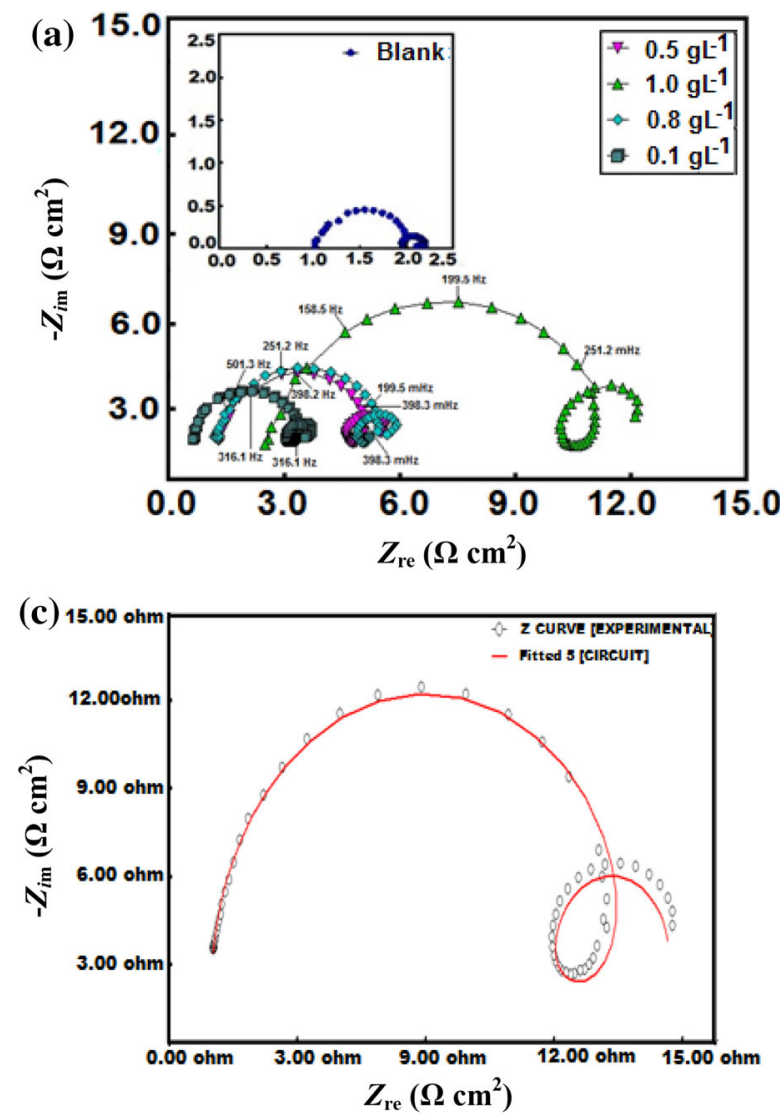

Fig. 3 a Nyquist plots for $\mathrm{AA}$ in $1 \mathrm{M} \mathrm{NaOH}$ without and with different concentrations of KLE at $303 \mathrm{~K}$. b Electrical equivalent circuit used for the analysis of impedance spectra. c Simulated and experimentally generated EIS (Nyquist) plot. d Bode ( $\log f$ vs. $\log |Z|)$

processes [29]. The inductive loop at intermediate frequencies imputed to relaxation of the adsorbed intermediate species $\left(\mathrm{OH}^{-}\right)$in the oxide layer, present on the metal surface [30]. The presence of inductive loop is reported in literature [31-35]. The second time constant of LF arises due to the adsorption and incorporation of hydroxide ions into the oxide film [36]

The impedance data is best described using an equivalent circuit mode displayed in Fig. 3b. Figure 3c clearly explains the fitting of an equivalent circuit model in Nyquist plot. The model consists of solution resistance (b)
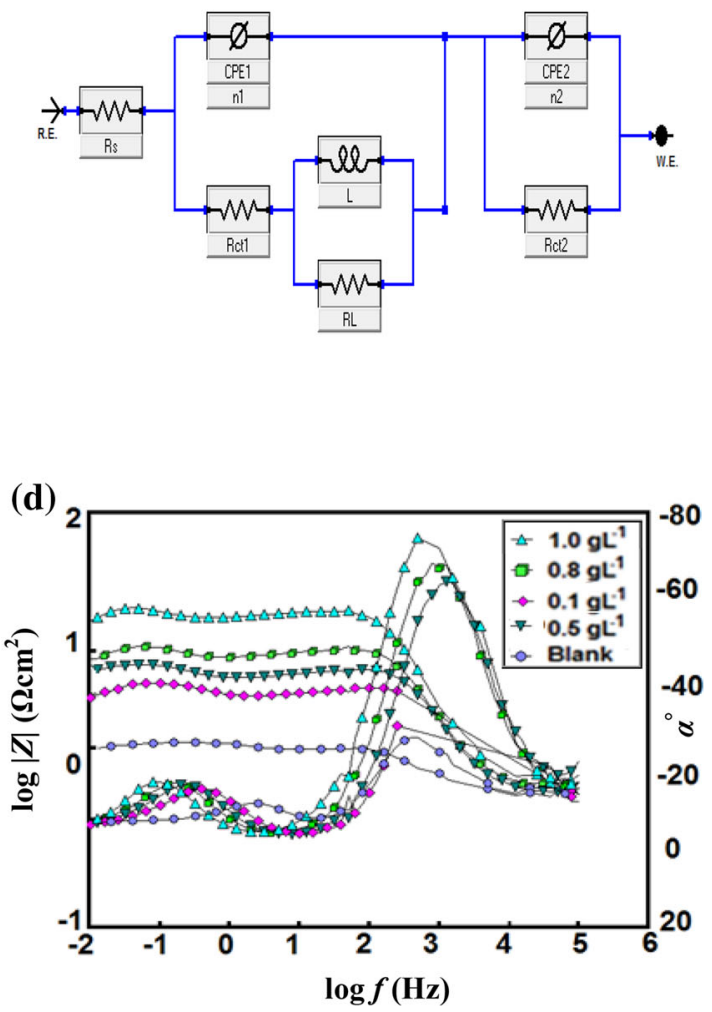

and phase angle $(\log f$ vs. $\alpha)$ plots of impendence spectra for AA in $1 \mathrm{M} \mathrm{NaOH}$ in absence and presence of different concentration of KLE at $303 \mathrm{~K}$

$\left(R_{\mathrm{S}}\right)$, inductance $(L)$, charge transfer resistance $\left(R_{\mathrm{ct}}\right)$ parallel to constant phase element $(C P E / Q)$.

This circuit includes another constant phase element $\left(C P E_{2}\right)$ which is placed in parallel to charge transfer resistance element $R_{c t 2}$. The $R_{c t 2}$ value is the measure of charge-transfer resistance corresponds to the $\mathrm{Al}^{+} \rightarrow \mathrm{Al}^{3+}$ reaction.

According to the reported mechanism $\mathrm{Al}$ dissolves into the solution in the form of $\mathrm{Al}^{3+}$ through the generation of $\mathrm{Al}^{+}$or $\mathrm{Al}^{2+}$ intermediate species [37]. Therefore, the polarization resistance, $R_{\mathrm{p}}$, might be represented by the 
sum of $R_{\mathrm{ct} 1}$ and $R_{\mathrm{ct} 2}$ in the equivalent circuit. Hence, $\eta \%$ is represented using $R_{\mathrm{p}}$ in following equation:

$\% \mathrm{IE}=\frac{R_{\mathrm{p}(\mathrm{inh})}-R_{\mathrm{p}}}{R_{\mathrm{p}(\mathrm{inh})}}$

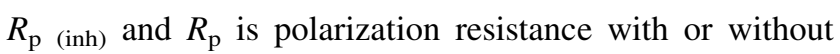
inhibitor.

Both $R_{\mathrm{ct}}$ and $R_{\mathrm{p}}$ value increases significantly with addition of KLE due to slower corrosion of electrode. The data in Table 3 reveals that increase in the values of charge transfer resistance is associated with a decrease in the double-layer capacitance at the whole concentration range. It may be stated that the constituents of KLE adsorbed on metal surface by replacing the water molecules at the metal surface which intern causes the decrease in the $C_{\mathrm{dl}}$ values. Thus, the rate of hydrogen evolution is reduced [38].

The double layer capacitance $\left(C_{\mathrm{dl}}\right)$ term is used to characterize the double layer at metal/solution interface by displaying the non ideal capacitive behavior. $C_{\mathrm{dl}}$ is calculated by the following relation [39]:

$C_{\mathrm{dl}}=Q \times\left(2 \Pi f_{\max }\right)^{a-1}$

A stepwise dissolution model has been proposed in Tafel measurements which require the stepwise addition of hydroxyl ions to metal/oxide interface. The inflow of hydroxyl ion is followed by the outflow of $\mathrm{Al}^{3+}$ ion across the interface. The adsorption of constituents of KLE is often a displacement reaction involving removal of adsorbed hydrated hydroxyl ions from the metal surface which is ascribed to the dielectric relaxation i.e., substitution of hydrated hydroxyl ions (high dielectric constant) with inhibitor molecules (low dielectric constant).

In the Bode spectra, three time constants are evident, namely, two time constants at high frequency (HF) low frequency (LF) regions and other time constant at middle frequency (MF) (Fig. 3d). Bode plot $(S)$ and phase angle $\left(\alpha^{\circ}\right)$ are used to describe the nature of pure capacitive behavior. In other words, the values of $S$ and $\alpha^{\circ}$ should be $-1^{\circ}$ and $-90^{\circ}$ for an ideal capacitor. However, this study shows the deviation from the ideal capacitive behavior at intermediate frequencies. In this case, the maximum slope value reaches up to -0.84 and the maximum phase angle is $-77^{\circ}$.

\section{Adsorption isotherm}

Adsorption process occurs through the replacement of water molecules by the inhibitor molecules at the metal surface within the electrical double layer to produce less pronounced dielectric effect.

Inhibitor $_{(\text {sol })}+n \mathrm{H}_{2} \mathrm{O}_{(\text {ads })} \leftrightarrow$ Inhibitor $_{(\text {ads })}+n \mathrm{H}_{2} \mathrm{O}_{(\text {sol })}$

The inhibitors may get adsorbed on the surface of aluminium and a protective film is formed. This restricts the diffusion of ions to or from the metal surface and hence retards the overall corrosion process. The interactions of the adsorbed inhibitor molecules with the metal surface may prevent the metal atoms from participating in the anodic reaction of the corrosion. This simple blocking effect decreases the number of metal atoms participating and hence decreases the corrosion rate.

Adsorption phenomenon is described to understand the nature of corrosion inhibition and it can be deduced in the term of adsorption isotherm. By fitting the various adsorption isotherms (including Freundlich, Temkin, Langmuir and Frumkin), Langmuir isotherm is best fitted and can be expressed by the following equation [40]:

$\frac{C_{\mathrm{inh}}}{\theta}=\frac{1}{K_{\mathrm{ads}}}+C_{\mathrm{inh}}$

where $K_{(\text {ads })}$ is adsorption equilibrium constant, $C$ denotes the concentration of inhibitor and $\theta$ represents the surface coverage.

The plots of $C / \theta$ and $C$ for the aluminium surface with different concentration of KLE give a straight line (Fig. 4) suggesting the adsorption of KLE constituents on the metal surface follows the Langmuir adsorption isotherm. It was found that $R^{2}$ and slope value obtained from Langmuir plots are close to 1 , which suggests that KLE inhibitor occupies one active site on the metal surface. The adsorption equilibrium constant $\left(K_{\mathrm{ads}}\right)$ is associated with

Table 3 Electrochemical impedance parameters for AA in $1 \mathrm{M} \mathrm{NaOH}$ in the absence and presence of different concentration of KLE at $303 \mathrm{~K}$

\begin{tabular}{|c|c|c|c|c|c|c|c|c|c|c|c|}
\hline $\begin{array}{l}\mathrm{KLE} \\
\left(\mathrm{g} \mathrm{L}^{-1}\right)\end{array}$ & $R_{\mathrm{s}}(\Omega)$ & $\begin{array}{l}Q_{1} \\
\left(\mathrm{~S} \Omega^{-1} \mathrm{~cm}^{-2}\right)\end{array}$ & $n$ & $\begin{array}{l}\left(R_{\mathrm{ct}}\right)_{1} \\
\left(\Omega \mathrm{cm}^{2}\right)\end{array}$ & $L\left(\mathrm{H} \mathrm{cm}^{2}\right)$ & $\begin{array}{l}R_{\mathrm{L}} \\
\left(\Omega \mathrm{cm}^{2}\right)\end{array}$ & $\begin{array}{l}Q_{2} \\
\left(\mathrm{~S} \Omega^{-1} \mathrm{~cm}^{-2}\right)\end{array}$ & $\begin{array}{l}\left(R_{\mathrm{ct}}\right)_{2} \\
\left(\Omega \mathrm{cm}^{2}\right)\end{array}$ & $\begin{array}{l}R_{\mathrm{p}} \\
\left(\Omega \mathrm{cm}^{2}\right)\end{array}$ & $\begin{array}{l}C_{\mathrm{dl}} \\
\left(\mu \mathrm{F} \mathrm{cm}{ }^{-2}\right)\end{array}$ & $\eta(\%)$ \\
\hline 0.0 & 1.023 & $500 \times 10^{-6}$ & 0.975 & 0.849 & 0.221 & 0.121 & $39.8 \times 10^{-6}$ & 0.188 & 1.037 & 413.8 & - \\
\hline 0.2 & 1.230 & $174 \times 10^{-6}$ & 0.979 & 1.934 & 0.189 & 2.268 & $51.2 \times 10^{-6}$ & 1.402 & 3.336 & 95.56 & 69.6 \\
\hline 0.5 & 1.023 & $151 \times 10^{-6}$ & 0.981 & 2.002 & 0.186 & 3.434 & $62.1 \times 10^{-6}$ & 1.739 & 3.741 & 78.05 & 72.2 \\
\hline 0.8 & 1.102 & $146 \times 10^{-6}$ & 0.989 & 2.987 & 0.199 & 2.340 & $68.8 \times 10^{-6}$ & 2.001 & 4.988 & 58.6 & 79.3 \\
\hline 1.0 & 1.034 & $104 \times 10^{-6}$ & 0.991 & 3.723 & 0.198 & 2.022 & $77.2 \times 10^{-6}$ & 2.114 & 5.837 & 49.9 & 82.24 \\
\hline
\end{tabular}




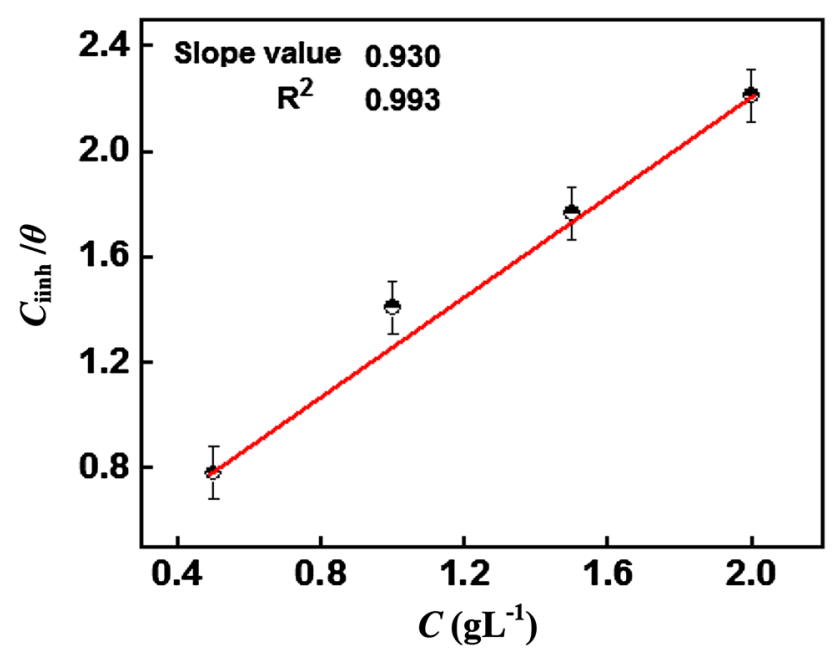

Fig. 4 Langmuir isotherm plot for adsorption of KLE molecule on $\mathrm{AA}$ in $1 \mathrm{M} \mathrm{NaOH}$

Table 4 Thermodynamic parameters for the adsorption of KLE molecules on AA at different concentration in $1 \mathrm{M} \mathrm{NaOH}$ at $303 \mathrm{~K}$

\begin{tabular}{llll}
\hline Inhibitors & Temperature $(\mathrm{K})$ & $K_{\text {ads }} 10^{3}\left(\mathrm{~g}^{-1}\right)$ & $G_{\text {ads }}{ }^{\circ}\left(\mathrm{KJ} \mathrm{mol}^{-1}\right)$ \\
\hline 0.2 & 303 & 2.1 & -15.21 \\
0.5 & 303 & 3.2 & -18.58 \\
0.8 & 303 & 4.0 & -20.33 \\
1.0 & 303 & 4.3 & -21.07 \\
\hline
\end{tabular}

standard free energy of adsorption $\Delta G^{\circ}$ (ads) by the following equation [41]:

$K_{\text {ads }}=\frac{1}{C_{\text {(solvent) }}} \exp \left(\frac{\Delta G_{\mathrm{ads}}^{\circ}}{R T}\right)$

where $R$ is universal gas constant, $T$ is the absolute temperature and $C$ is the concentration of water $\left(1000 \mathrm{~g} \mathrm{~L}^{-1}\right)$. The values of $K_{\text {ads }}$ is representing here in $\mathrm{g}^{-1} \mathrm{~L}$. So, in equation, the concentration of water is taken in $\mathrm{g} \mathrm{L}^{-1}$ in place of $55.5 \mathrm{~mol} \mathrm{~L}^{-1}$.

The values of $K_{(\mathrm{ads})}$ and $\Delta G_{(\mathrm{ads})}{ }^{\circ}$ were calculated and given in Table 4. It is seen that the negative value of $\Delta G^{\circ}$ is found in all cases. In literature, it has been shown that the values of $\Delta G_{(\mathrm{ads})}{ }^{\circ}$ up to $-20 \mathrm{~kJ} \mathrm{~mol}^{-1}$ are consistent with electrostatic interaction between charged molecules and a charged metal surface (physical adsorption), while those around $-40 \mathrm{~kJ} \mathrm{~mol}^{-1}$ or higher corresponds to the charge sharing or charge transfer from the inhibitor molecules to the metal surface to form a co-ordinate type of bond (chemisorption) [42]. In this study, it is clear from the Table 4 that the values of $\Delta G_{(\mathrm{ads})}{ }^{\circ}$ is in the range of -15 to $-21 \mathrm{~kJ} \mathrm{~mol}^{-1}$ i.e., the inhibitor adsorbed on the metal surface is in accordance with physical adsorption.

\section{Surface morphology study}

The SEM micrograph of corroded metal surface in $\mathrm{NaOH}$ is displayed in Fig. 5a. It can be seen that surface damage appears due to aggressive attack of alkaline media. In contrast, after treating the surface with inhibitor, the smoothness of the aluminium surface (Fig. 5b) results due to the formation of adsorption film on it.

Atomic force microscope (AFM) was used to investigate the corrosion inhibition ability of the extract to characterize the microstructure of AA surface. Figure 6 depicts threedimensional AFM images of AA surface after $3 \mathrm{~h}$ exposure in $1 \mathrm{M} \mathrm{NaOH}$ at $303 \mathrm{~K}$. In uninhibited system, the AA surface was fairly damaged due to dissolution in corrosive medium (Fig. 6a) with maximum height scale of $600 \mathrm{~nm}$. The maximum height scale of inhibited AA surface (Fig. 6b) was $150 \mathrm{~nm}$ which indicates the smoothness of metal surface after treating with KLE.

\section{Conclusion}

1. Aqueous extract of KLE is an environmentally benign good corrosion inhibitor for AA in alkaline. Inhibition efficiency increases with increasing the concentration of extracts.

2. Tafel polarization indicates cathodic type inhibition through KLE.
Fig. 5 SEM micrographs of a uninhibited and $\mathbf{b}$ inhibited AA sample containing 1.0 $\mathrm{g} \mathrm{L}^{-1}$ of $\mathrm{KLE}$ in $1 \mathrm{M} \mathrm{NaOH}$
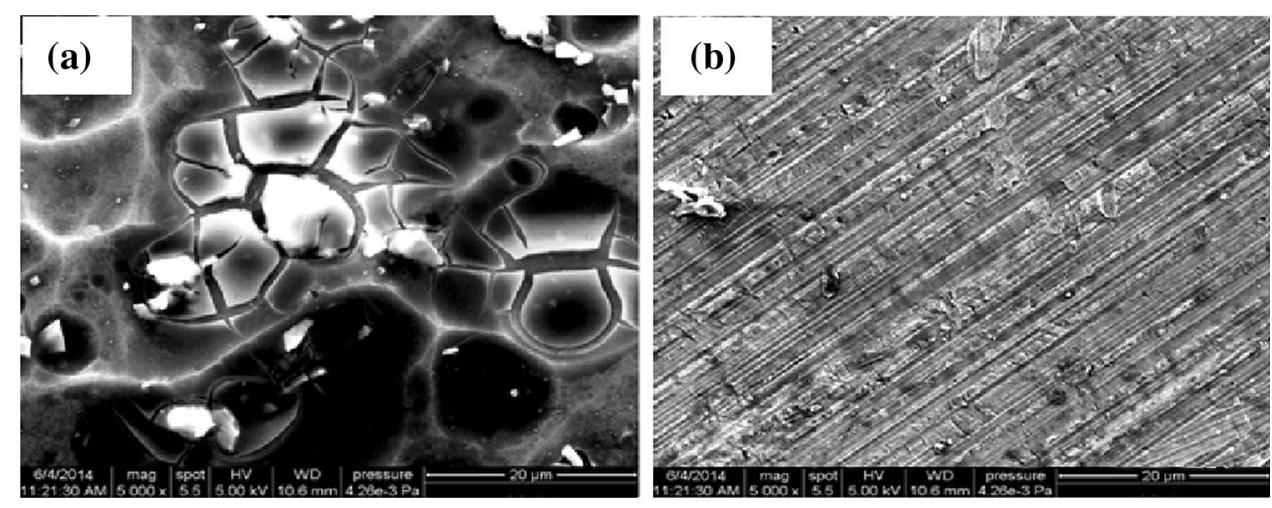

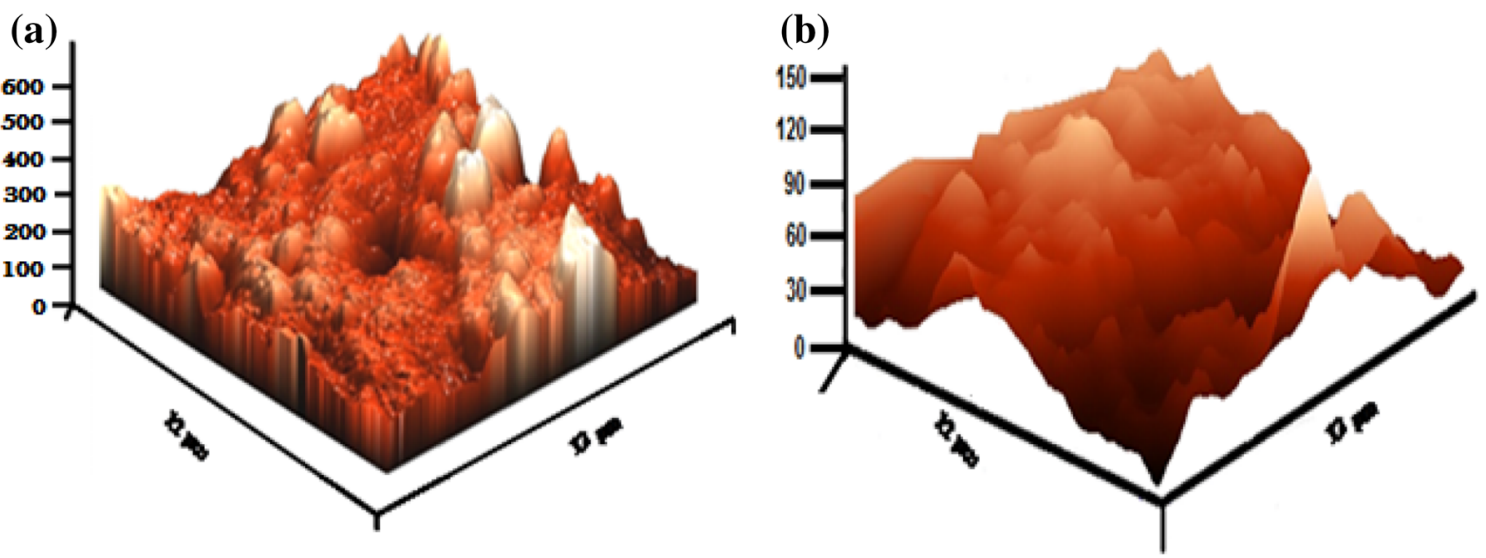

Fig. 6 AFM images of a uninhibited and b inhibited AA sample containing $1.0 \mathrm{~g} \mathrm{~L}^{-1}$ of KLE in $1 \mathrm{M} \mathrm{NaOH}$

3. Adsorption of the KLE molecule on the AA surface in $\mathrm{NaOH}$ obeys the Langmuir's isotherm.

4. EIS indicates that increase in $R_{\mathrm{ct}}$ and decrease in $C_{\mathrm{dl}}$ is observed which is explained by decrease in local dielectric constant and or an increase in the electrical double layer thickness due to the adsorbed inhibitor molecules at the metal/solution interface.

Acknowledgements Authors are highly thankful to Prof. V. B. Singh, Head (Department of chemistry), B.H.U. for providing SEM and AFM facilities for successful completion of my research work.

Open Access This article is distributed under the terms of the Creative Commons Attribution 4.0 International License (http://creative commons.org/licenses/by/4.0/), which permits unrestricted use, distribution, and reproduction in any medium, provided you give appropriate credit to the original author(s) and the source, provide a link to the Creative Commons license, and indicate if changes were made.

\section{References}

1. Chaubey N, Yadav DK, Singh VK, Quraishi MA (2015) A comparative study of leaves extracts for corrosion inhibition effect on aluminium alloy in alkaline medium. Ain Shams Eng J. doi:10.1016/j.asej.2015.08.020

2. Amin MA, Abd EI-Rehim SS, El-Sherbini EEF, Hazzazi OA, Abbas MN (2009) Polyacrylic acid as a corrosion inhibitor for aluminium in weakly alkaline solutions. Part I: Weight loss, polarization, impedance EFM and EDX studies. Corros Sci 51:658-667

3. Oguzie EE (2007) Corrosion inhibition of aluminium in acidic and alkaline media by Sansevieria trifasciata extract. Corros Sci 49:1527-1539

4. Soliman HN (2011) Influence of 8-hydroxyquinoline addition on the corrosion behavior of commercial $\mathrm{Al}$ and $\mathrm{Al}-\mathrm{HO} 411$ alloys in $\mathrm{NaOH}$ aqueous media. Corros Sci 53:2994-3006

5. Mercier D, Barthes-Labrousse MG (2009) The role of chelating agents on the corrosion mechanisms of aluminium in alkaline aqueous solutions. Corros Sci 51:339-348

6. Onuchukwu AI (1990) The inhibition of aluminium corrosion in an alkaline medium II: Influence of hard bases. Mater Chem Phys $24: 337-341$
7. Pyun SI, Moon SM, Ahn SH, Kim SS (1999) Effects of $\mathrm{Cl}^{-}$, $\mathrm{NO}_{3}{ }^{-}$and $\mathrm{SO}_{4}{ }^{2-}$ ions on anodic dissolution of pure aluminium in alkaline solution. Corros Sci 41:653-667

8. Abdel-Gaber AM, Khamis E, Abo-ElDahab H, Adeel S (2008) Inhibition of aluminium corrosion in alkaline solutions using natural compound. Mater Chem Phys 109:297-305

9. Irshedat MK, Nawafleh EM, Bataineh TT, Muhaidat R, Al-Qudaha MA, Alomary AA (2013) Investigations of the Inhibition of Aluminium Corrosion in $1 \mathrm{M} \mathrm{NaOH}$ Solution by Lupinus varius 1. extract. Port Electrochim Acta 31:1-10

10. Al Shboula TMA, Jazzazi TMA, Bataineh TT, Al-Qudah MA, Alrawashdeh AI (2014) Inhibition of corrosion of aluminium in $\mathrm{NaOH}$ solution by leave extract of Mesembryanthemum nodiflorum. Jordan J Chem 9:149-158

11. Umoren SA, Obot IB, Ebenso EE, Obi-Egbedi NO (2009) The Inhibition of aluminium corrosion in hydrochloric acid solution by exudate gum from Raphia hookeri. Desalination 247:561-572

12. Abiola OK, Otaigbe JOE (2009) The effects of Phyllanthus amarus extract on corrosion and kinetics of corrosion process of aluminium in alkaline solution. Corros Sci 51:2790-2793

13. Emran KM, Ahmed NM, Torjoman BA, Al-Ahmadi AA, Sheekh SN (2014) Cantaloupe extracts as eco friendly corrosion inhibitors for aluminium in acidic and alkaline solutions. J Mate Environ Sci 5:1940-1950

14. Abiola OK, Otaigbe JOE, Kio OJ (2009) Gossipium hirsutum L. extracts as green corrosion inhibitor for aluminium in $\mathrm{NaOH}$ solution. Corros Sci 51:1879-1881

15. Umoren SA, Inam EI, Udoidong AA, Obot IB, Ubong UM, Kim KW (2015) Humic acid from livestock dung: ecofriendly corrosion inhibitor for 3SR aluminum alloy in alkaline medium. Chem Eng Commun 202:206-216

16. Umoren SA, Obot IB, Ebenso EE, Okafor PC, Ogbobe O, Oguzie EE (2006) Gum arabic as a potential corrosion inhibitor for aluminium in alkaline medium and its adsorption characteristics. Anti-corros Methods Mater 53:277-282

17. Umoren SA, Obot IB, Akpabio LE, Etuk SE (2008) Adsorption and corrosive inhibitive properties of Vigna unguiculata in alkaline and acidic media. Pigm Resin Technol 37:98-105

18. Chaubey N, Singh VK, Quraishi MA (2015) Effect of some peel extracts on the corrosion behavior of aluminium alloy in alkaline medium. Int J Ind Chem. doi:10.1007/s40090-015-0054-8

19. Singh A, Meena AK, Sudeep Meena, Pant P, Padhi MM (2012) Studies on standardisation of Andrographis paniculata nees and identification by HPTLC using andrographolide as marker compound. Int J Pharm Pharm Sci 4:197-200 
20. Singh A, Singh VK, Quraishi MA (2010) Aqueous extract of Kalmegh (Andrographis paniculata) leaves as green inhibitor for mild steel in hydrochloric acid solution. Int J Corros. doi:10. $1155 / 2010 / 275983$

21. Ansari KR, Quraishi MA (2015) Experimental and quantum chemical evaluation of Schiff bases of isatin as a new and green corrosion inhibitors for mild steel in $20 \% \mathrm{H}_{2} \mathrm{SO}_{4}$. J Taiwan Inst Chem E 54:145-154

22. Kyung KL, Kim KB (2014) Electrochemical impedance characteristics of pure $\mathrm{Al}$ and $\mathrm{Al}-\mathrm{Sn}$ alloys in $\mathrm{NaOH}$ solution. Corros Sci 43:561-575

23. Awad SA, Kamel KHM, Kassab A (1979) Corrosion behavior of aluminium in $\mathrm{NaOH}$ solutions. Electroanal Chem 105:291-294

24. Amin MA, Abd. EI-Rehim SS, F Essam, EI-Sherbini Mohsen NA (2009) Polyacrylic acid as a corrosion inhibitor for aluminium in weakly alkaline solutions. Part I: Weight loss, polarization, impedance EFM and EDX studies. Corros Sci 51:658-667

25. Wang JB, Wang JM, Shao HB, Zhang JQ, Cao CN (2007) The corrosion and electrochemical behavior of pure aluminium in alkaline methanol solutions. J Appl Electrochem 37:753-758

26. Aksut KCE, Abbas A (2000) The behavior of aluminum in alkaline media. Corros Sci 42:2051-2067

27. Brett CMA (1989) Studies on aluminium corrosion in hydrochloric acid solution. Portug Electrochim Acta 7:123-126

28. Khaled KF (2010) Electrochemical investigation and modeling of corrosion inhibition of aluminum in molar nitric acid using some sulphur-containing amines. Corros Sci 52:2905-2916

29. Lenderink HJW, Linden MVD, Wit JHWD (1993) Corrosion of aluminium in acidic and neutral solutions. Electrochim Acta 38:1989-1992

30. Ahamed I, Khan S, Ansari KR, Quraishi MA (2011) Primaquine: a pharmaceutically active compound as corrosion inhibitor for mild steel in hydrochloric acid solution. J Chem Pharm Res 3:703-717

31. Bessone JC, Mayer C, Juttner K, Lorenz WJ (1983) AC impedance measurements of aluminum barrier type oxide films. Electrochim Acta 28:171-175

32. Frers SE, Stefnel MM, Mayer C, Chierchie T (1990) AC-Impedance measurements on aluminium in chloride containing solutions and below the pitting potential. J Appl Electrochem 20:996-999

33. Bessone JB, Salinas DR, Mayer CE, Ebert E, Lorenz WJ (1992) An EIS study of aluminium barrier-type oxide films formed in different media. Electrochim Acta 37:2283-2290

34. Brett CMA (1990) The application of electrochemical impedance techniques to aluminium corrosion in acidic chloride solution. J Appl Electrochem 20:1000-1003

35. Macdonald DD (1990) Review of mechanistic analysis by electrochemical impedance spectroscopy. Electrochim Acta 35:1509-1525

36. Prabhu D, Rao P (2014) Corrosion behaviour of 6063 aluminium alloy in acidic and in alkaline media. Arab J Chem. doi:10.1016/j. arabjc.2013.07.059

37. Al-Kharafi FM, Badawy WA (1998) Inhibition of corrosion of Al 6061, aluminum, and an aluminum-copper alloy in chloride-free aqueous media: Part 2-Behavior in basic solutions. Corrosion $54: 377-385$

38. Ansari KR, Quraishi MA (2014) Bis-Schiff bases of isatin as new and environmentally benign corrosion inhibitor for mild steel. J Ind Eng Chem 20:2819-2829

39. Chaubey N, Savita Singh VK, Quraishi MA (2015) Corrosion inhibition performance of different bark extracts on aluminium in alkaline solution. JAAUBAS. doi:10.1016/j.jaubas.2015.12.003

40. Ansari KR, Quraishi MA, Singh A (2015) Pyridine derivatives as corrosion inhibitors for $\mathrm{N} 80$ steel in $15 \% \mathrm{HCl}$ : Electrochemical, surface and quantum chemical studies. '. Measurement 76:136-147

41. Chaubey N, Singh VK, Quraishi MA (2016) Alstonia Scholaris bark as an environmentally benign corrosion inhibitor for aluminium alloy in sodium hydroxide solution. J Mater Environ Sci 7:2453-2467

42. Madkour LH, Elroby SK (2015) Inhibitive properties, thermodynamic, kinetics and quantum chemical calculations of polydentate Schiff base compounds as corrosion inhibitors for iron in acidic and alkaline media. Int J Ind Chem. doi:10.1007/s40090015-0039-7 